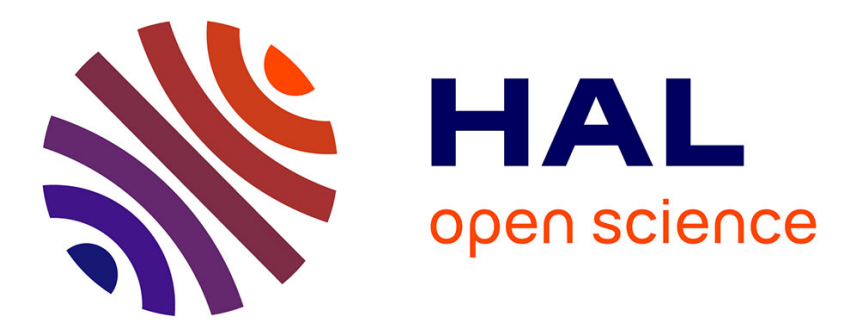

\title{
Baboons' hand preference resists to spatial factors for a communicative gesture but not for a simple manipulative action
}

Marie Bourjade, Hélène Meunier, Catherine Blois-Heulin, Jacques Vauclair

\section{- To cite this version:}

Marie Bourjade, Hélène Meunier, Catherine Blois-Heulin, Jacques Vauclair. Baboons' hand preference resists to spatial factors for a communicative gesture but not for a simple manipulative action. Developmental Psychobiology, 2013, 55 (6), pp.651-661. 10.1002/dev.21128 . hal-01021749

\author{
HAL Id: hal-01021749 \\ https://hal.science/hal-01021749
}

Submitted on 3 Dec 2015

HAL is a multi-disciplinary open access archive for the deposit and dissemination of scientific research documents, whether they are published or not. The documents may come from teaching and research institutions in France or abroad, or from public or private research centers.
L'archive ouverte pluridisciplinaire HAL, est destinée au dépôt et à la diffusion de documents scientifiques de niveau recherche, publiés ou non, émanant des établissements d'enseignement et de recherche français ou étrangers, des laboratoires publics ou privés. 


\section{Baboons' hand preference resist to spatial factors for a communicative gesture but not for a simple manipulative action}

\begin{tabular}{|r|l|}
\hline Journal: & Developmental Psychobiology \\
\hline Manuscript ID: & DEV-12-139.R1 \\
\hline Wiley - Manuscript type: & Research Article \\
\hline Date Submitted by the Author: & n/a \\
\hline Complete List of Authors: & $\begin{array}{l}\text { Bourjade, Marie; Aix-Marseille University, Research Centre in the } \\
\text { Psychology of Cognition, Language and Emotion } \\
\text { Meunier, Hélène; Primatology Centre of Strasbourg University, } \\
\text { Blois-Heulin, Catherine; Université de Rennes 1, UMR 6552 Ethos « } \\
\text { Ethologie Animale et Humaine » } \\
\text { Vauclair, Jacques; Aix-Marseille University, Research Centre in the } \\
\text { Psychology of Cognition, Language and Emotion }\end{array}$ \\
\hline Keywords: & $\begin{array}{l}\text { Communication, Handedness, Hemispheric Specialization, Language, } \\
\text { Laterality }\end{array}$ \\
\hline
\end{tabular}


Running title: Strong hand preference for gesturing in baboons

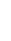

10

11

12

14

15

16

17

18

19

20

22

23

25

26

27

29

30

31

33

34

35

36

37

38

39

40

41

42

44

45

46

47

48

49

51

52

53

54

55

57

58

59

60 
1 Baboons' hand preference resist to spatial factors for a communicative

2

3

4

5

$6{ }^{1}$ Research Centre in the Psychology of Cognition, Language and Emotion, Aix-Marseille

7 University, Aix-en-Provence, France

$8{ }^{2}$ Primatology Centre of Strasbourg University, Fort Foch, 67207 Niederhausbergen, France

$9{ }^{3}$ UMR 6552 Ethos « Ethologie Animale et Humaine », Université de Rennes 1 - CNRS,

10 Station biologique, Paimpont, France

11

12

13 Corresponding author:

14 Marie Bourjade

15 Research Center in the Psychology of Cognition, Language and Emotion, PsyCLE, Aix-

16 Marseille University, 29 av. Schuman, 13621 Aix-en-Provence Cedex 1, France

17 marie.bourjade@univ-amu.fr, marie.bourjade@gmail.com

$18+033612415088$

gesture but not for a simple manipulative action

36 
20 Olive baboons (Papio anubis) do acquire and use intentional requesting gestures in

21 experimental contexts. Individual's hand preference for these gestures is consistent with that

22 observed for typical communicative gestures, but not for manipulative actions. Here, we

23 examine whether the strength of hand preference may also be a good marker of hemispheric

24 specialization for communicative gestures, hence differing from the strength of hand

25 preference for manipulative actions. We compared the consistency of individuals' hand

26 preference with regard to the variation in space of either (i) a communicative partner or (ii) a

27 food item to grasp using a controlled set-up. We report more consistent hand preference for

28 communicative gestures than for grasping actions. Established hand preference in the midline

29 was stronger for gesturing than for grasping and allowed to predict the consistency of hand

30 preference across positions. We found no significant relation between the direction of hand

31 preference and the task.

32

Key words: Handedness, Laterality, Language, Gesture, Hand preference, Olive baboon 
41 Handedness is by far the most overwhelming manifestation of behavioral asymmetry in

42 humans. A right-hand preference is shown by approximately ninety percent of humans

43 (Annett, 1985; Knecht et al., 2000a), and this population-level bias is considered universal

44 because of its existence across all modern cultures (Coren \& Porac, 1977; Raymond \&

45

46

47

Pontier, 2004) and over the course of human evolution (Cashmore, Uomini, \& Chapelain, 2008; Faurie \& Raymond, 2004; Uomini, 2009). From a neurofunctional viewpoint, handedness is also one robust manifestation of hemispheric specialization, the other one being language lateralization (Hopkins \& Vauclair, 2012). Indeed, right-handers are left-hemisphere dominant for hand functions and most humans are also left hemisphere dominant for language functions. Both features have hence been argued to evolve concomitantly during the course of human evolution (Crow, 2004; Ettlinger, 1988; Waren, 1980).

However, recent studies have emphasized that handedness would actually be only a poor predictor of hemispheric dominance for language. First, a majority of left-handers are also left hemisphere dominant for language in humans (Knecht et al., 2000b; Khedr, Hamed, Said, \& Basahi, 2002). Moreover, asymmetries in the use of limbs are not specific to humans but are widespread in vertebrates instead (Hopkins, 2007; Rogers \& Andrew, 2002; Vallortigara, Rogers, \& Bisazza, 1999). It has hence been proposed that handedness predated language (Corballis, Badzakova-Trajkov, \& Häberling, 2012; Forrester, Quaresmini, Leavens, Mareschal, \& Thomas, 2013) and there is still considerable debate about whether lefthemisphere dominance for language was inherited from hemispheric specialization for its motor components (Greenfield 1991; Forrester et al., 2013) or rather its communicative components (Vauclair, 2004). In that respect, communicative gestures that imply both motor and communicative hand functions have been of particular interest in the recent years. Children point more frequently with their right hand (Bates, O’Connell, Vaid, Sledge, \& Oakes, 1986; Cochet \& Vauclair, 2010), even if they are left-handers or ambidextrous for 
66

67

manipulating objects otherwise (Vauclair \& Imbault, 2009). Interestingly hand preference

may be more pronounced for communicative gestures such as pointing than for object manipulation, and both types of hand preference are usually poorly correlated in human infants (Cochet \& Vauclair, 2010; Jacquet, Esseily, Rider, \& Fagard, 2012; Vauclair \& Imbault, 2009). This has led some to hypothesize that hand preference for communicative gestures may be a better marker of hemispheric specialization for language than handedness (Cochet \& Vauclair, 2010; Kimura, 1993; Vauclair, 2004).

Further support for this hypothesis comes from comparative work conducted with nonhuman primates. Several studies have for example found right-sided asymmetries at the population level in both the chimpanzee (Hopkins et al., 2005; Meguerditchian, Vauclair, \& Hopkins, 2010) and the baboon (Meguerditchian, Molesti, \& Vauclair, 2011b; Meguerditchian \& Vauclair, 2006) for a range of manual tasks, including complex (i.e., bimanual) manipulations and communicative gestures. As it is the case for children (Esseily, Jacquet, \& Fagard, 2011; Jacquet et al., 2012; Vauclair \& Imbault, 2009), the population-level right biases found in both species were stronger for communicative gestures than for objectdirected manual actions, (e.g. baboons: Meguerditchian \& Vauclair, 2009; chimpanzees: Hopkins et al., 2005; Meguerditchian et al., 2010). Consequently, a similar pattern of hand preference can be observed in human and in some non-human primates (see also Meunier, Vauclair, \& Fagard, 2012b; Meunier et al., this issue), albeit in different proportions. Taken together, these data suggest that the left-hemisphere dominance in linguistic functioning is not modality-specific and may have deep phylogenetic origins (Corballis et al., 2012;

Meguerditchian, Cochet, \& Vauclair, 2011a; Vauclair, 2004).

In two studies conducted in our laboratory, we found that baboons were able to request food intentionally from a human partner using either pointing (Meunier, Prieur, \& Vauclair, 2012a) or food-begging gestures (Bourjade, Meguerditchian, Maille, \& Vauclair, submitted). 
91 While both gestures are communicative, presumed difference exists since pointing, but not

92 begging, requires attracting the attention of a human towards an external distinct target and

93 has been suggested to involve higher cognitive demands in monkeys (e.g. Hattori, Kuroshima,

$94 \&$ Fujita, 2010). Interestingly, the pattern of laterality for pointing was similar in baboons and

95 human infants (Meunier et al., 2012b), while it has not been investigated so far for food-

96 begging. As regards food-begging, baboons were shown to keep their hand preference

97 consistent with a typical communicative gesture (i.e., hand slapping), but not with object-

98 directed manual actions (Meguerditchian \& Vauclair, 2009). The authors hypothesized that

99 baboons' communicative gestures, as regards the direction and consistency of hand

100 preference, may rely on a specific left-lateralized cerebral system that would be independent

101 from the system controlling purely manipulative actions (Meguerditchian et al., 2011a).

102 However, overall direction of hand preference may not be the only aspect that has

103 neuropsychological significance. Handedness is commonly measured as a discrete variable

104 based on the predominant use of the right or the left hand, or equivalent use of both hands. In

105 contrast, many have suggested that measuring handedness on a continuous scale accounted for

106 both the direction and the strength of hand preference, with the latter also being a good

107 marker of brain specialization (e.g. Bishop, Ross, Daniels, \& Bright, 1996; Dassonville, Zhu,

108 Ugurbil, Kim, \& Ashe, 1997; Khedr et al., 2002; Vallortigara et al., 1999). Neurofunctional

109 evidence supports this claim since the strength and direction of handedness seem to be coded

110 separately in the human brain (Dassonville et al., 1997). Likewise, it could be alternately

111 hypothesized that the strength of hand preference for communicative gestures, defined as the

112 proportion of same-hand use for a given gesture, may be a good marker of hemispheric

113 specialization for communicative hand functions in baboons, hence differing from the

114 strength of hand preference for manipulative actions. 
In this contribution, we examine these two hypotheses alternately using a standardized

116

117

118

119

120

121

122

123

124

125

126

127

128

129

130

131

132

133

134

135

136

137

138

measure for quantifying consistency of hand preference as a tool towards validation (i.e.,

QHP task, Bishop et al., 1996). The initial task developed in humans was to pick up playing

cards. The use of the non-preferred hand was encouraged by varying the spatial position of

the cards in relation to the body midline. The prediction was that switching hand across

positions indicated weaker preferences than keeping hand consistent across positions.

Adaptations of this task for children (Esseily et al., 2011; Jacquet et al., 2012) and non-human

primates (Chapelain et al., 2012; Meunier, Blois-Heulin, \& Vauclair, 2011; Meunier et al.,

2012b; Meunier et al., this issue) have proved recently successful in highlighting the influence of situational factors on handedness for reaching actions.

Our aim of adapting this paradigm here was to use the sensitivity to situational factors as a means of measuring the robustness of hand preference of subjects predefined as righthanded, left-handed, ambiguously-handed, but also those established as exclusively-handed and non-exclusively handed irrespective of the direction of laterality. The rationale was then to determine the consistency of hand preference across spatial positions (herein: consistency of hand preference) in two different tasks, taking established hand preference (i.e., both in direction and strength) in the central position as a reference. We built on previously published data reporting hand preference for grasping in baboons (Meunier et al., 2011) to compare with novel data reporting hand preference for food-begging measured on same individuals within the same experimental setting. In order to portray the differential lateralization of communicative and non-communicative hand functions, we examined the consistency across positions of both the direction and the strength of individuals' hand preference with regards to the variation in space of (i) a communicative partner (i.e., food-begging) and (ii) a food item to grasp (i.e., grasping). 
Based on previously published research reporting stronger biases for communicative

140 gestures than for grasping actions at the population level (Meguerditchian \& Vauclair, 2009;

141 Meunier et al., 2011; Meunier et al., 2012b), we expected hand preference to be more

142 consistent across positions in the communicative than in the non-communicative context.

143 Additionally, if the cerebral system controlling for communicative gestures differs from the

144 system controlling manipulative actions on the basis of the direction but not strength of hand

145 preference, we would expect more established right-handers than left-handers in the central

146 position for food-begging than for grasping, and the direction of the established preference to

147 predict the propensity to switch from preferred to non preferred hand. Alternately, if the two

148 systems differ on the basis of the strength but not direction of hand preference, we would

149 expect baboons to show stronger established hand preference for food-begging than for

150 grasping, and the strength of the established preference to predict the propensity to switch

151 from preferred to non preferred hand.

152

153 METHODS

\section{Animals}

155 The experiments took place in the Primate Station of the Centre National de la Recherche

156 Scientifique, Rousset, France. Initially, 42 olive baboons (Papio anubis) were presented with

157 the grasping task between September and December 2009 (see Meunier et al., 2011 for

158 details). Two years later, 13 out of these subjects were presented with a food-begging task.

159 These subjects had previously learnt to request food by extending an arm through the cage in

160 former experiments (e.g. Bourjade et al., submitted; Meunier et al., 2012a). Only the data for

161 these 13 subjects that have completed the two tasks are presented here. Subjects were five

162 females and eight males, all adult. All lived in social groups and were housed either in 
163 outdoor parks or large cages with free access to an indoor shelter. Water was available ad

164 libitum and subjects were never deprived of food or water during testing. All subjects had

165 been tested in their outdoor area, and only females were partly isolated from dominant

166 individuals (i.e., that were kept inside) during testing for the food-begging task. All

167 procedures complied with the current French laws and the European directive 86/609/CEE.

\section{Experimental procedure}

170 For the two tasks, the experimental set-up was an adaptation of the Bishop's QHP task

171 initially developed to test pre-defined human right-handers for their degree of hand preference

172 (Bishop et al., 1996). In the original task seven picture cards were placed on a semi-circle,

173 each positioned 30 degrees apart from one another, in front of- and within the reach of the

174 participant. Participants stood in front of the template and had to pick up specific cards one by

175 one to put them in a box located in front of them. Hand preference was sampled by recording

176 the hand used to pick up each card. This task has been thereafter adapted to non-human

177 primates in a very comparable set-up (Chapelain et al., 2012; Meunier et al., 2011; Meunier et

178 al, this issue). We provide a brief description of the experimental set-up here. Full details of

179 the methods and procedures are available elsewhere (Chapelain et al., 2012; Meunier et al.,

180 2011; Meunier et al., 2012b).

We used a similar apparatus for both tasks. Subjects sat down a concrete block fixed

182 perpendicularly to the mesh inside the cage at about $90 \mathrm{~cm}$ from the ground. There was a

$18310 \times 60 \mathrm{~cm}$ hole in the wire-mesh that allowed the subject to pass its arms through. Two video

184 cameras were placed $2 \mathrm{~m}$ in front of the cage on both sides of the experimenter with an angle

185 of $45^{\circ}$ to the subject's midline. For the food-begging task only, subjects were additionally

186 provided with a bottle hung inside the cage, filled with diluted fruit juice to prevent them 
187 orienting their body towards the experimenter, particularly when she positioned laterally (see 188 supplementary material).

189

190

191

192

193

194

195

196

197

198

199

200

201

202

203

204

205

206

207

208

209

210

For the grasping task, the playing card was replaced by a food item that was randomly and successively placed at one of the seven positions placed at $30^{\circ}$ from each other on a semicircle drawn on a tray fixed outside of the wire-mesh (Figure 1a). Only one item, i.e., a raisin, was placed at a time and the experimenter randomly used her right or left hand to place it.

Hand preference had been sampled by recording the hand used by subjects to grasp the raisin.

For the food-begging task, the playing card was replaced by the experimenter herself holding a piece of food in one hand. The experimenter randomly and successively positioned herself at one of the positions placed at $30^{\circ}$ from each other on a $1 \mathrm{~m}$ radius semi-circle drawn on a textile sheet lying on the ground in front of the subject's cage (Figure 1b). The experimenter approached the apparatus from one meter away, always starting from the midline and heading towards the position to be tested. The experimenter randomly used her right or left hand to hold the piece of food, i.e., a $2 \mathrm{~cm}$ piece of banana. Hand preference was sampled by recording the hand used by subjects to beg for food.

Note that for the food-begging task five positions only could be reliably scored. The two most extreme positions that had not been tested for food-begging were therefore not considered anymore in the present paper for grasping. Consequently, the five remaining positions (i.e., corresponding to positions 2 to 6 in Meunier et al., 2011) were: extreme left (LL), left (L), central (C), right (R) and extreme right (RR) from the left to the right of the subject (Figure 1). For each task, the order of presentation of the positions was randomized beforehand and then, the same order was presented for all subjects. The trials were scored as valid or invalid on subsequent video analysis. A valid trial was considered when the subject sat in front of the setup aligned with the middle of the apparatus. Video material was coded by 
211 two independent observers whose one was naïve to the experimental procedure. We only kept

212 the trials that have been scored as valid by the two observers for further analysis. Thus,

213 subjects reached 20 to 60 valid trials per position for grasping and 8 to 35 valid trials per

214 position for food-begging.

\section{Data analysis}

217 The direction of hand preference was determined with binomial tests on the number of right

218 and left responses of each individual for each task and each position to evaluate departure

219 from chance level and categorize individuals as right-, left- or ambiguously-handed

220 accordingly. Handedness Index (HI) was calculated for each task and position by subtracting

221 the number of left-handed responses from the number of right-handed responses and then

222 dividing by the total number of responses (Hopkins, 1999). HI ranged from -1.0 to +1.0 with

223 positive values indicating right-hand bias and negative values left-hand bias. The strength of

224 hand preference was assessed thanks to the absolute value of $\mathrm{HI}$ (ABSHI) ranging from 0 to 1.

225 Subjects displaying a significant bias in any position were categorized as lateralized for these

226 positions. Subjects with ABSHI = 1 were categorized as exclusively-handed, the other

227 subjects as non-exclusively-handed. When referring to individuals as right-, left-, exclusively-

228 or non-exclusively-handed or as lateralized, we referred to individual's established hand

229 preference in the central position for each task.

We applied generalized linear mixed models (GLMM) to our data in order to

231 investigate the influence of situational factors as a function of the task. Several models were

232 fitted with the proportion of right-handed over total responses of each individual in each

233 position and each task as dependent variable (see summary of models fitted as supplementary

234 material). Depending on the models, fixed effects were alternately or simultaneously (i) the 
235 position, (ii) the task, (iii) the subject's sex and (iv) the interactions between them. The

236 positive correlation amongst observations of the same individual was taken into consideration

237 by adding the individual or the interaction between individual and position as random effect,

238 which allowed each individual to respond differently to positions (Brown \& Prescott, 2006).

239 The family chosen for the dependent variable in the models was Binomial with a Logit link

240 function; model selection was based on the Akaike Information Criteria (AIC; Onyango,

241 2009).

242 As the rationale of the QHP task was to foster subjects on to switch from their

243 preferred to non-preferred hand in the contralateral hemispace, we counted the number of

244 subjects that switched hand at 30 and 60 degrees in the non-preferred contralateral hemispace.

245 As almost all subjects, but two, that switched hand did so at $30^{\circ}$ in the contralateral

246 hemispace, we considered this angle only for statistical analysis. Non-parametric statistics

247 (Siegel \& Castellan, 1988) were performed on such categorical data, as well as ABSHI and

248 individual's mean HI for each task and each position. All tests were performed with R 2.10.1

249 software (http://cran.r-project.org) with level of significance set at 0.05 .

250

251 RESULTS

252 Comparison between tasks on the basis of the direction of hand preference

253 The baboons did not display similar patterns of direction of hand preference for food-begging

254 and for grasping (i.e. best fitting model, $\mathrm{AIC}=690.6$; Table 1). There was a significant effect

255 of the task on the proportion of right-handed responses (Wald Test, $\mathrm{z}=-4.23, \mathrm{p}<0.001$ ), and

256 a significant interaction between task and position (Figure 2). It means that the direction of

257 hand preference varied as a function of both task and position, with baboons being more right-

258 handed for food-begging than for grasping in the position LL (Wald test, $\mathrm{z}=-9.92, \mathrm{p}<0.001$ ) 
259 and position $\mathrm{L}$ (Wald test, $\mathrm{z}=-8.02, \mathrm{p}<0.001$ ), and more right-handed for grasping than for 260 food-begging in the position $\mathrm{R}$ (Wald test, $\mathrm{z}=11.54, \mathrm{p}<0.001$ ) and position $\mathrm{RR}$ (Wald test, $\mathrm{z}$ $261=10.83, \mathrm{p}<0.001)$. Irrespective of the task, baboons were overall more right-handed than 262 left-handed for position $\mathrm{R}$ (Wald test, $\mathrm{z}=2.23, \mathrm{p}=0.026$ ), but not for positions $\mathrm{RR}$ (Wald 263 test, $\mathrm{z}=0.71, \mathrm{p}=0.473$ ), $\mathrm{L}$ (Wald test, $\mathrm{z}=-0.81, \mathrm{p}=0.417$ ) and LL (Wald test, $\mathrm{z}=-0.55, \mathrm{p}=$ $2640.583)$.

265 Each baboon did not keep similar hand preference for food-begging and for grasping 266 based on handedness index (HI). HI did not correlate between tasks for all positions 267 (Spearman correlation coefficients, position LL: $r=0.17, p$ 0.573; position $\mathrm{L}: \mathrm{r}=0.21, \mathrm{p}=$ 268 0.483; position $\mathrm{C}: \mathrm{r}=0.39, \mathrm{p}=0.184$; position $\mathrm{RR}: \mathrm{r}=0.44, \mathrm{p}=0.127$ ), except position $\mathrm{R}$ 269 (Spearman correlation coefficient, $\mathrm{r}=0.58, \mathrm{p}=0.037$ ). The average $\mathrm{HI}$ across all positions for 270 each individual did not correlate between tasks (Spearman correlation coefficient, $\mathrm{r}=0.34, \mathrm{p}$ $271=0.252)$

\section{Comparison between tasks on the basis of the strength of hand preference}

274 The baboons did not display similar patterns of strength of hand preference for food-begging 275 and for grasping when considering ABSHI across positions (Figure 4). The strength of hand 276 preference was affected overall by the position of the item to grasp (Friedman analysis of 277 variance, $F(4)=29.97, \mathrm{p}<0.001$ ) but not by the position of the experimenter whom to beg 278 from (Friedman analysis of variance, $F(4)=1.55, \mathrm{p}=0.834$ ). Direct comparisons between the 279 two tasks in each position reveal that the strength of hand preference was significantly higher 280 for food-begging than for grasping in the central position (one-sample permutation test, $\mathrm{t}=$ $2812.01, \mathrm{p}=0.042$ ), while it was significantly lower in the position LL (one-sample permutation 282 test, $\mathrm{t}=-2.02, \mathrm{p}=0.039$ ). There was no significant difference in the strength of hand 
283 preference between the two tasks for the positions RR, R and L (one-sample permutation

284 tests, $p>0.05$ in all cases).

285

286

287

288

289

290

291

292

293

294

295

296

297

298

299

300

301

302

303

304

305

306

This result is gaining support by the fact that the consistency of hand preference across positions also varied as a function of the task. Based on established hand preference in the central position (Tables $2 \& 3$ ), lateralized baboons were more likely to switch from preferred to non-preferred hand in the contralateral space for grasping than for food-begging, irrespective of the direction of laterality (Fisher exact probabilities test, $\mathrm{p}=0.002$ ).

\section{Discriminatory power of direction versus strength of hand preference}

For hand preference established in the central position (Tables $2 \& 3$ ), we found no significant difference between the number of right-handed and left-handed baboons as a function of the task (Fisher exact probabilities test, $p=1$ ), while we found more exclusively-handed baboons than non-exclusively handed baboons for food-begging than for grasping (Fisher exact probabilities test, $\mathrm{p}=0.002$ ). Eight subjects out of 13 displayed exclusive hand preference for food-begging whereas no subject displayed exclusive hand preference for grasping in the midline.

The strength of hand preference established in the central position for food-begging (i.e., as exclusively- or non-exclusively-handed baboons) allowed predicting the propensity of individuals to switch from preferred to non-preferred hand in the contralateral hemispace (Fisher exact probabilities test, $\mathrm{p}=0.022$, Table 3 ). All the eight baboons that had exclusive hand preference for food-begging in the central position kept their preferred hand in the contralateral hemispace, while the two lateralized baboons that had non-exclusive hand preference in the central position switched to non-preferred hand at 30 degrees in the contralateral hemispace. However, the direction of hand preference established in the central 
307 position, did not allow predicting the propensity of individuals to switch from preferred to

308 non-preferred hand in the contralateral hemispace for grasping (Fisher exact probabilities test, $309 \mathrm{p}=1$, Table 2), nor for food-begging (Fisher exact probabilities test, $\mathrm{p}=0.444$, Table 3 ).

\section{DISCUSSION}

312 Three main points are worth noting in the present contribution. First, the differential

313 distribution of hand biases for gesturing toward a partner and for grasping an item

314 corroborates previous results obtained in baboons and other species (Meunier et al., 2012b;

315 Meunier et al., this issue) and stresses that these two manual actions seem not to be processed

316 similarly by the brain. Second, this investigation sheds light on the relative influence of the

317 strength of hand preference in distinguishing communicative from non-communicative tasks

318 in an old-world-monkey. Third, these results clearly state that situational factors have little

319 influence on hand preference for gesturing in a communicative context, as reported in

320 macaques (Meunier et al., this issue), chimpanzees (Hopkins \& Wesley, 2002) and human

321 infants (Jacquet et al., 2012).

322

\section{Influence of the nature of the task on hand preference}

324

325
Our examination that compared hand use for grasping and for food-begging pointed out differential use of the right hand according to situational factors. Baboons hardly ever used their right hand to grasp a raisin situated on their left side, but used more often their right hand for begging from an experimenter located at same positions. Conversely, subjects used their right hand more often to grasp a raisin situated on their right than to beg for food from an experimenter situated on their right. These findings indicate that the position in space largely 
330 influences hand use for grasping but not hand use for requesting food from a partner. This is

331 supported by the fact that baboons did not keep the direction of their hand preference

332 consistent between tasks. Handedness indices measured on same individuals for the two tasks

333 were very poorly correlated, except for the position R. The reason why these two indices

334 correlate for this position only is not straightforward. As observed in humans for different

335 activities (Steenhuis, 1999), left-handed baboons may be more likely to switch hand for

336 gesturing in the contralateral hemispace than right-handed baboons, but it does not explain

337 why a similar trend was not observed for the extreme right position.

The tasks also elicited different patterns of strength of hand preference across

339 positions. At the group level, the strength of hand preference for grasping a raisin in the

340 extreme rightward and leftward positions was high, whereas it was low in the more central

341 positions. Contrarily, the measures of strength for food-begging did not vary across positions.

342 In other words, situational factors do not affect the strength of hand preference for food-

343 begging while they affect the strength of hand preference for grasping. At the individual level,

344 this task-related effect underlies two opposite patterns of occurrences of hand switch. In the

345 contralateral hemispace subjects kept their preferred hand for begging for food, but switched

346 to non-preferred hand for grasping, irrespective of the direction of hand preference. Together,

347 these findings illustrate that the more pronounced biases for communicative gestures than for

348 object manipulation recorded at the population level (Meguerditchian \& Vauclair, 2009;

349 Meunier et al., 2011; Meunier et al., 2012b) are underpinned by stronger hand preference at

350 the individual level for communicative gestures than for grasping.

351 Such a differential effect of situational factors on hand preference is in line with the

352 few available studies that have compared handedness for different manual tasks and/or

353 species using the QHP task. For instance, it had been found that the direction of hand

354 preference was strongly affected by the position of an item to grasp in mangabeys and 
355 Campbell's monkeys (Chapelain et al., 2012). In a comparative work, Meunier and colleagues

356 (2012b; this issue) highlighted convergent distributions of hand biases in macaques, baboons

357 and human infants, with patterns very similar to ours. Human infants have otherwise been

358 shown to use more their right hand to point to objects than to grasp them and to be more

359 willing to use their right hand in the contralateral left hemispace for pointing than for grasping

360 (Jacquet et al., 2012). These collective data, all gathered with a similar experimental set-up

361 (the QHP task), support the hypothesis that functional asymmetries for gesturing in a

362 communicative context and for grasping may develop quite independently in humans and

363 non-human primates, perhaps due to differential constraints on their expression.

\section{Significance of the direction and the strength of hand preference}

366 Both right-handed and left-handed baboons for grasping switched from preferred to non-

367 preferred hand in the contralateral hemispace, while both right-handed and left-handed

368 baboons for begging kept their preferred hand in the contralateral hemispace. This suggests

369 that the direction of hand preference does not discriminate between the tasks, at least in our

370 sample. Our data show however that the strength of hand preference in the midline may be a

371 good predictor of the consistency of hand preference across positions, at least for food-

372 begging. Three results are worth noting. First, the strength of baboons' hand preference was

373 higher for food-begging than for grasping in the midline. Second, none of the subjects had

374 exclusive preferences for one hand in the grasping task, whereas almost all of them had

375 exclusive preferences for one hand in the food-begging task. Third, the baboons with

376 established exclusive preferences for food-begging in the midline were less likely to switch

377 hand across positions than the baboons with established non-exclusive preferences. Therefore, 
378 baboons' hand preference seems to differ between tasks on the basis of the strength of hand

379 preference, rather than the direction.

380

381

382

383

384

385

386

387

388

389

390

391

392

393

394

395

396

397

398

399

400

401

These results are gaining support from neuroimaging evidence in humans of a

continuous relation between the strength of handedness and functional activation of the motor

cortex (Dassonville et al., 1997). These authors found both right and left-handers having

similar contralateral activation of the motor cortex concomitant to the use of the dominant

hand. However, the strength of hand preference correlated negatively with the cerebral

activation ipsilateral to the dominant hand. It means that activation in the motor cortex is

more lateralized with increasing strength of handedness in both right-handers and left-

handers. Additional research is needed to confirm whether the strength of hand preference

might have similar neurofunctional significance in non-human primates.

Although human infants (Cochet \& Vauclair, 2010; Esseily et al., 2011; Jacquet et al., 2012; Vauclair \& Imbault, 2009), like chimpanzees and baboons (Hopkins et al., 2005;

Meguerditchian et al., 2010; Meguerditchian \& Vauclair, 2009), have been reported to be more right-handed for gesturing than for manipulating objects, it is worth noting that no population-level bias emerged in the present data. It is possible that our sample size was too small to detect any population-level bias for food-begging. As proposed above, it could alternately be that the strength of hand preference for communicative gestures may be a better marker of hemispheric specialization than the direction of hand preference for the use of learnt gestures in baboons. As the direction of hand preference may be partly determined by epigenetic constraints (Schaafsma, Riedstra, Pfannkuche, Bouma, \& Groothuis, 2009;

Vallortigara et al., 1999), it is possible that brain specialization for these gestures may have been constrained by individual learning history, leading to differential lateralization at the population level. It would explain why the population right-sided bias was found lower for 
402 food-begging than for typical gestures in baboons, though both indices correlate nevertheless

403 (Meguerditchian \& Vauclair, 2009).

404

405

\section{Conclusion}

406

Baboons show stronger hand preference for communicative gestures than for

407 manipulative action irrespective of the direction of laterality. Hand preference for gesturing is

408 little influenced by situational factors and this consistency can be predicted by the strength of

409 hand preference in the midline. Based on these findings, we suggest that behavioral

410 asymmetries for gestural communication and for manipulative actions in baboons rely on

411 independent brain processes that differ with the strength of hand preference, possibly

412 reflecting differential degrees of lateralization in brain activation. Additional research is

413 needed to evaluate whether the apparent behavioral continuity that exists between baboons,

414 chimpanzees and humans with respect to manual asymmetries has neurological

415 underpinnings.

416

417 NOTES

418 This research was supported by a French National Research Agency (ANR) grant; reference

419 ANR-08-BLAN-0011_01. We thank Quentin Wohlfarth for re-coding all the video material,

420 Simon Faber, Céline Gouyet, Benoît Rosay, Morgane Allanic, Mathilde Hervieux and

421 Ludivine Glas for helping in data collection, Georges Di Grandi and Sébastien Guiol for their

422 help in conceiving the apparatus, and the caretakers of the Primate Station of Rousset for their

423 helpful assistance throughout the experiments. 
425

426

427

428

429

430

431

432

433

434

435

436

437

438

439

440

441

442

443

444

445

446

447

448

\section{References}

Annett, M. (1985). Left, right, hand and brain: The right shift theory. Oxford, UK:

Psychology Press.

Bates, E., O’Connell, B., Vaid, J., Sledge, P., \& Oakes, L. (1986). Language and hand preference in early development. Developmental Neuropsychology, 2(1), 1-15.

Bishop, D. V. M., Ross, V. A., Daniels, M. S., \& Bright, P. (1996). The measurement of hand preference: A validation study comparing three groups of right-handers. British Journal of Psychology, 87(2), 269-285.

Bourjade, M., Meguerditchian, A., Maille, A., \& Vauclair, J. (submitted). Attribution of attention as a prerequisite of intentional gesturing in baboons (Papio anubis).

Brown, H., \& Prescott, R. (2006). Applied Mixed Models in Medicine. New York, NY: John Wiley \& Sons.

Cashmore, L., Uomini, N., \& Chapelain, A. (2008). The evolution of handedness in humans and great apes: a review and current issues. Journal of Anthropological Sciences, 86, 7-35.

Chapelain, A., Laurence, A., Vimond, M., Maille, A., Meunier, H., Fagard, J., ... BloisHeulin, C. (2012). Hand preference and its flexibility according to the position of the object: a study in cercopithecines examining spontaneous behaviour and an experimental task (the Bishop QHP task). Animal Cognition, 15(5), 937-953.

Cochet, H., \& Vauclair, J. (2010). Pointing gesture in young children: Hand preference and language development. Gesture, 10(2-3), 129-149.

Corballis, M. C., Badzakova-Trajkov, G., \& Häberling, I. S. (2012). Right hand, left brain: genetic and evolutionary bases of cerebral asymmetries for language and manual action. Wiley Interdisciplinary Reviews: Cognitive Science, 3(1), 1-17. 
Coren, S., \& Porac, C. (1977). Fifty centuries of right-handedness: The historical record.

450 Science, 198(4317), 631-632.

451

452

453

454

455

456

457

458

459

460

461

462

463

464

465

466

467

468

469

470

471

472

Crow, T. (2004). Directional asymmetry is the key to the origin of modern Homo sapiens (the Broca-Annett axiom): A reply to Rogers' review of the speciation of modern homo sapiens. Laterality: Asymmetries of Body, Brain and Cognition, 9(2), 233-242.

Dassonville, P., Zhu, X.-H., Ugurbil, K., Kim, S.-G., \& Ashe, J. (1997). Functional activation in motor cortex reflects the direction and the degree of handedness. Proceedings of the National Academy of Sciences, 94(25), 14015-14018.

Esseily, R., Jacquet, A.-Y., \& Fagard, J. (2011). Handedness for grasping objects and pointing and the development of language in 14-month-old infants. Laterality: Asymmetries of Body, Brain and Cognition, 16(5), 565-585.

Ettlinger, G. (1988). Hand preference, ability, and hemispheric specialization: In how far are these factors related in the monkey? Cortex: A Journal Devoted to the Study of the Nervous System and Behavior, 24(3), 389-398.

Faurie, C., \& Raymond, M. (2004). Handedness frequency over more than ten thousand years. Proceedings of the Royal Society B: Biological Sciences, 271(Suppl_3), S43-S45.

Forrester, G.S., Quaresmini, C., Leavens, D., Mareschal, D., \& Thomas, M.S.C. (2013). Human handedness: an inherited evolutionary trait. Behavioural Brain Research, 237, 200-206.

Greenfield, P.M. (1991). Language tools and the brain: the ontogeny and phylogeny of hierarchically organized sequential behavior. Behavioral Brain Sciences, 14, 531-550.

Hattori, Y., Kuroshima, H., \& Fujita, K. (2010). Tufted capuchin monkeys (Cebus apella) show understanding of human attentional states when requesting food held by a human. Animal Cognition, 13(1), 87-92. 
473 Hopkins, W. D. (1999). On the other hand: statistical issues in the assessment and

474 interpretation of hand preference data in nonhuman primates. International Journal of

$475 \quad$ Primatology, 20(6), 851-866.

476 Hopkins, W. D. (Ed.). (2007). The evolution of hemispheric specialization in primates. New

$477 \quad$ York, NY: Academic Press.

478 Hopkins, W. D., Russell, J., Freeman, H., Buehler, N., Reynolds, E., \& Schapiro, S. J. (2005).

479 The distribution and development of handedness for manual gestures in captive

480 chimpanzees (Pan troglodytes). Psychological Science, 16(6), 487-493.

481 Hopkins, W. D., \& Vauclair, J. (2012). Evolution of behavioral and brain asymmetries in

482 primates. In M. Tallerman \& K.R. Gibson (Eds.), Handbook of language evolution (p.

483 184-197). Oxford, UK: Oxford University Press.

484 Hopkins, W. D., \& Wesley, M. J. (2002). Gestural communication in chimpanzees (Pan

485 troglodytes): The influence of experimenter position on gesture type and hand

486 preference. Laterality: Asymmetries of Body, Brain and Cognition, 7(1), 19-30.

487 Jacquet, A.-Y., Esseily, R., Rider, D., \& Fagard, J. (2012). Handedness for grasping objects

488 and declarative pointing: A longitudinal study. Developmental Psychobiology, 54(1), $489 \quad 36-46$.

490 Khedr, E.M., Hamed, E., Said, A., \& Basahi, J. (2002). Handedeness and language cerebral 491 lateralization. European Journal of Applied Physiology, 87(4-5), 469-473.

492 Kimura, D. (1993). Neuromotor mechanisms in human communication. Oxford, UK:

$493 \quad$ University Press.

494 Knecht, S., Deppe, M., Dräger, B., Bobe, L., Lohmann, H., Ringelstein, E.-B., \& Henningsen, 495 H. (2000a). Language lateralization in healthy right-handers. Brain, 123(1), 74-81. 
496 Knecht, S., Dräger, B., Deppe, M., Bobe, L., Lohmann, H., Flöel, A., ... Henningsen, H.

497 (2000b). Handedness and hemispheric language dominance in healthy humans. Brain, $498 \quad 123(12), 2512-2518$.

499 Meguerditchian, A., Cochet, H., \& Vauclair, J. (2011a). From gesture to language

500 Ontogenetic and phylogenetic perspectives on gestural communication and its cerebral

501 lateralization. In A. Vilain, C. Abry, J.-L. Schwartz, \& J. Vauclair (Eds.), Primate

502 Communication and Human Language: Vocalization, Gestures, Imitation and Deixis

503 in Humans and Non-Humans (p. 91-120). Amsterdam, The Netherlands: John

$504 \quad$ Benjamins Publishing.

505 Meguerditchian, A., Molesti, S., \& Vauclair, J. (2011b). Right-handedness predominance in

506162 baboons (Papio anubis) for gestural communication: Consistency across time and 507 groups. Behavioral Neuroscience, 125(4), 653-660.

508 Meguerditchian, A., \& Vauclair, J. (2006). Baboons communicate with their right hand.

$509 \quad$ Behavioural Brain Research, 171(1), 170-174.

510 Meguerditchian, A., \& Vauclair, J. (2009). Contrast of hand preferences between

511 communicative gestures and non-communicative actions in baboons: Implications for

512 the origins of hemispheric specialization for language. Brain and Language, 108(3),

$513 \quad 167-174$.

514 Meguerditchian, A., Vauclair, J., \& Hopkins, W. D. (2010). Captive chimpanzees use their

515 right hand to communicate with each other: Implications for the origin of the cerebral

516 substrate for language. Cortex, 46(1), 40-48.

517 Meunier, H., Blois-Heulin, C., \& Vauclair, J. (2011). A new tool for measuring hand

518 preference in non-human primates: Adaptation of Bishop's quantifying hand

519 preference task for olive baboons. Behavioural Brain Research, 218(1), 1-7. 
520 Meunier, H., Fagard, J., Maugard, A., Briseno, M., Fizet, J., Canteloup, C., .. Vauclair, J.

521 Patterns of hemispheric specialization for a communicative gesture in different

522 primates species. Developmental Psychobiology, this issue.

523 Meunier, H., Prieur, J., \& Vauclair, J. (2012a). Olive baboons communicate intentionally by

524 pointing. Animal Cognition, DOI:10.1007/s10071-012-0558-y.

525 Meunier, H., Vauclair, J., \& Fagard, J. (2012b). Human infants and baboons show the same

526 pattern of handedness for a communicative gesture. PLoS ONE, 7(3), e33959.

527 Onyango, N. O. (2009). On the linear mixed effects regression (lmer) $\mathrm{r}$ function for nested

528 animal breeding data. Case Studies In Business, Industry And Government Statistics,

$529 \quad 4(1), 44-58$.

530 Raymond, M., \& Pontier, D. (2004). Is there geographical variation in human handedness?

$531 \quad$ Laterality, 9(1), 35-51.

532 Rogers, L. J., \& Andrew, R. (Eds.). (2002). Comparative vertebrate lateralization. Cambridge,

$533 \quad$ UK: University Press.

534 Schaafsma, S. M., Riedstra, B. J., Pfannkuche, K. A., Bouma, A., \& Groothuis, T. G. G.

535 (2009). Epigenesis of behavioural lateralization in humans and other animals.

536 Philosophical Transactions of the Royal Society B: Biological Sciences, 364(1519),

$537 \quad 915-927$.

538 Siegel, S., \& Castellan, N. (1988). Nonparametric statistics for the behavioral sciences.

$539 \quad$ Berkeley, CA: McGraw-Hill.

540 Steenhuis, R. E. (1999). The relation between hand preference and hand performance: what

541 you get depends on what you measure. Laterality: Asymmetries of Body, Brain and

$542 \quad$ Cognition, 4(1), 3-26.

543 Uomini, N. T. (2009). The prehistory of handedness: Archaeological data and comparative 544 ethology. Journal of Human Evolution, 57(4), 411-419. 
545 Vallortigara, G., Rogers, L. ., \& Bisazza, A. (1999). Possible evolutionary origins of cognitive 546 brain lateralization. Brain Research Reviews, 30(2), 164-175.

547 Vauclair, J. (2004). Lateralization of communicative signals in nonhuman primates and the 548 hypothesis of the gestural origin of language. Interaction Studies, 5(3), 365-386.

549 Vauclair, J., \& Imbault, J. (2009). Relationship between manual preferences for object 550 manipulation and pointing gestures in infants and toddlers. Developmental Science, $551 \quad 12(6), 1060-1069$.

552 Waren, J. M. (1980). Handedness and laterality in humans and other animals. Physiological $553 \quad$ Psychology, 8(3), 351-359.

554

555

556

557

558

559

560

561

562

563

564

565

566

567

568

569

570 
571 Table 1. Summary of models fitted with the proportion of right-handed responses as

572 dependent variable. Interactions between two effects are represented by colons. Bold

573 characters indicate the best fitting model, which significantly differed from the null model

574 fitted without fixed effects (Chi-square tests for the log-likelihood ratios, $\mathrm{p}<0.001)$.

575

\begin{tabular}{|c|c|c|c|c|}
\hline Dependent variable & Model & Fixed effects & Random effects & AIC \\
\hline \multicolumn{5}{|c|}{ Proportion of right-handed responses } \\
\hline & 1 & none & individual & 4292 \\
\hline & 2 & task & individual & 4283 \\
\hline & 3 & task & individual:position & 1676 \\
\hline & 4 & position & individual & 1717 \\
\hline & 5 & position & individual:position & 1659 \\
\hline & 6 & task, position, task:position & individual & 820 \\
\hline & 7 & task, position, task:position & individual:position & 691 \\
\hline & 8 & task, sex, position, task:sex & individual & 1624 \\
\hline & 9 & task, sex, position, task:sex & individual:position & 1690 \\
\hline
\end{tabular}

576

577 
Table 2. Raw data for each individual tested in the grasping task

\begin{tabular}{|c|c|c|c|c|c|c|c|c|c|c|c|c|c|c|c|c|c|c|c|c|c|}
\hline \multirow[t]{2}{*}{ Individual } & \multirow[t]{2}{*}{ Sex } & \multicolumn{4}{|c|}{ LL } & \multicolumn{4}{|c|}{$\mathrm{L}$} & \multicolumn{4}{|c|}{$\mathrm{C}$} & \multicolumn{4}{|c|}{$\mathrm{R}$} & \multicolumn{4}{|c|}{$\mathrm{RR}$} \\
\hline & & $\mathrm{LH}$ & $\mathrm{RH}$ & B test & $\mathrm{HI}$ & $\mathrm{LH}$ & $\mathrm{RH}$ & B test & $\mathrm{HI}$ & $\mathrm{LH}$ & $\mathrm{RH}$ & B test & $\mathrm{HI}$ & $\mathrm{LH}$ & $\mathrm{RH}$ & B test & $\mathrm{HI}$ & $\mathrm{LH}$ & $\mathrm{RH}$ & B test & $\mathrm{HI}$ \\
\hline Anelka & M & 50 & 10 & $<0.001$ & -0.67 & 36 & 24 & 0.155 & -0.20 & 19 & 41 & 0.006 & 0.37 & 1 & 59 & $<0.001$ & 0.97 & 0 & 60 & $<0.001$ & 1.00 \\
\hline Katy & $\mathrm{F}$ & 60 & 0 & $<0.001$ & -1.00 & 53 & 7 & $<0.001$ & -0.77 & 17 & 43 & 0.001 & 0.43 & 2 & 58 & $<0.001$ & 0.93 & 1 & 59 & $<0.001$ & 0.97 \\
\hline Marius & M & 60 & 0 & $<0.001$ & -1.00 & 60 & 0 & $<0.001$ & -1.00 & 29 & 31 & 0.897 & 0.03 & 1 & 59 & $<0.001$ & 0.97 & 0 & 60 & $<0.001$ & 1.00 \\
\hline Momo & M & 60 & 0 & $<0.001$ & -1.00 & 60 & 0 & $<0.001$ & -1.00 & 54 & 6 & $<0.001$ & -0.80 & 0 & 60 & $<0.001$ & 1.00 & 0 & 60 & $<0.001$ & 1.00 \\
\hline Oscar & $\mathrm{M}$ & 59 & 1 & $<0.001$ & -0.97 & 60 & 0 & $<0.001$ & -1.00 & 50 & 10 & $<0.001$ & -0.67 & 1 & 59 & $<0.001$ & 0.97 & 0 & 60 & $<0.001$ & 1.00 \\
\hline Perfide & $\mathrm{F}$ & 60 & 0 & $<0.001$ & -1.00 & 57 & 3 & $<0.001$ & -0.90 & 37 & 23 & 0.092 & -0.23 & 12 & 48 & $<0.001$ & 0.60 & 0 & 60 & $<0.001$ & 1.00 \\
\hline Prise & $F$ & 55 & 5 & $<0.001$ & -0.83 & 46 & 14 & $<0.001$ & -0.53 & 28 & 32 & 0.699 & 0.07 & 4 & 56 & $<0.001$ & 0.87 & 4 & 56 & $<0.001$ & 0.87 \\
\hline Rodolphe & M & 60 & 0 & $<0.001$ & -1.00 & 60 & 0 & $<0.001$ & -1.00 & 57 & 3 & $<0.001$ & -0.90 & 5 & 55 & $<0.001$ & 0.83 & 0 & 60 & $<0.001$ & 1.00 \\
\hline Sestarde & $\mathrm{F}$ & 18 & 2 & $<0.001$ & -0.80 & 9 & 11 & 0.412 & 0.10 & 2 & 18 & $<0.001$ & 0.80 & 0 & 20 & $<0.001$ & 1.00 & 0 & 20 & $<0.001$ & 1.00 \\
\hline Toti & M & 60 & 0 & $<0.001$ & -1.00 & 60 & 0 & $<0.001$ & -1.00 & 37 & 23 & 0.092 & -0.23 & 1 & 59 & $<0.001$ & 0.97 & 0 & 60 & $<0.001$ & 1.00 \\
\hline Tulie & $\mathrm{F}$ & 60 & 0 & $<0.001$ & -1.00 & 57 & 3 & $<0.001$ & -0.90 & 38 & 22 & 0.052 & -0.27 & 10 & 50 & $<0.001$ & 0.67 & 1 & 59 & $<0.001$ & 0.97 \\
\hline Ubu & M & 60 & 0 & $<0.001$ & -1.00 & 60 & 0 & $<0.001$ & -1.00 & 49 & 11 & $<0.001$ & -0.63 & 3 & 57 & $<0.001$ & 0.90 & 2 & 58 & $<0.001$ & 0.93 \\
\hline Uranus & M & 60 & 0 & $<0.001$ & -1.00 & 51 & 9 & $<0.001$ & -0.70 & 32 & 28 & 0.698 & -0.07 & 2 & 58 & $<0.001$ & 0.93 & 0 & 60 & $<0.001$ & 1.00 \\
\hline \multicolumn{3}{|c|}{ Handedness category } & & & & & & & & & $\mathrm{C}$ & & & & & & & & & & \\
\hline $\mathrm{LH}-\mathrm{RH}$ & & 13 & 0 & & & 11 & 0 & & & 4 & 3 & 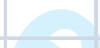 & & 0 & 13 & & & 0 & 13 & & \\
\hline LAT & & & & 13 & & & & 11 & & & & 7 & A & & & 13 & & & & 13 & \\
\hline EXC & & & & & 9 & & & & 6 & & & 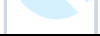 & 0 & & & & 2 & & & & 9 \\
\hline
\end{tabular}

EXC

Sex: $M$ male, $F$ female. Main columns: $L H$ number of left-handed responses, $R H$ number of right-handed responses, $B$ test p-value of the 
Table 3. Raw data for each individual tested in the food-begging task

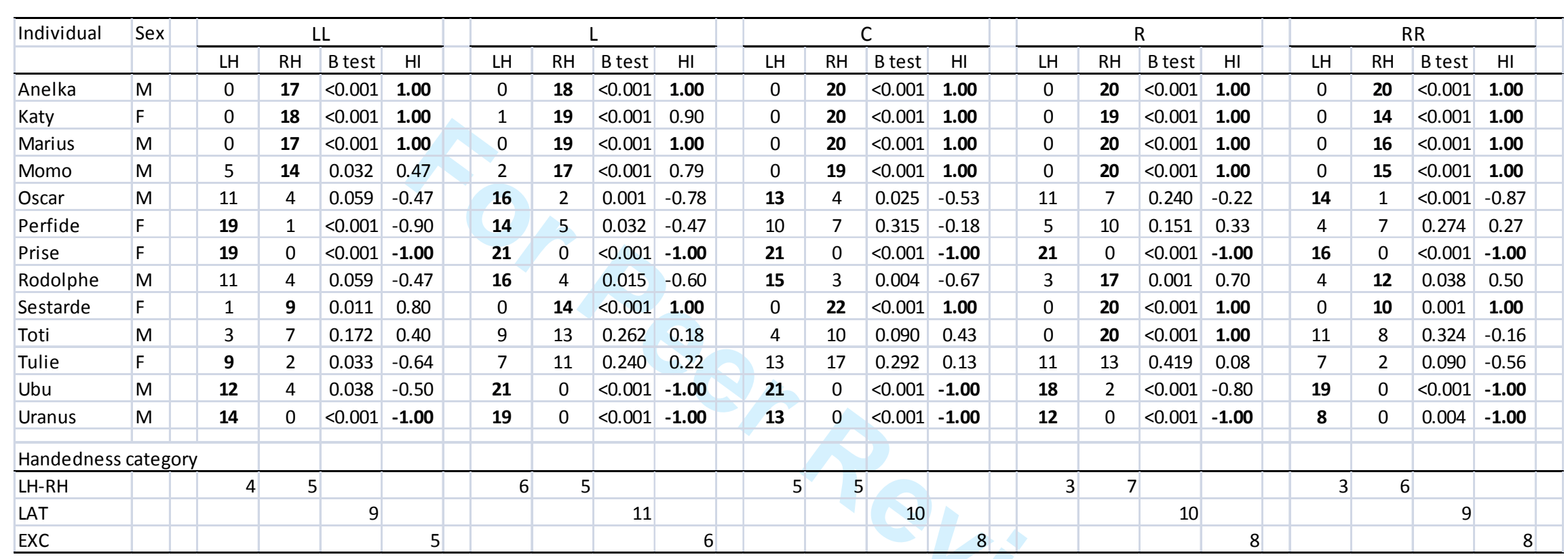

Sex: $M$ male, $F$ female. Main columns: $L H$ number of left-handed responses, $R H$ number of right-handed responses, $B$ test $\mathrm{p}$-value of the

591 baboons $(\mathrm{HI}=1$ or $\mathrm{HI}=-1)$. 


\section{Captions}

593

594 Figure 1. Experimental set-up of (a) the grasping task and (b) the food-begging task

595

596 Figure 2. Mean percentages $( \pm$ SEM) of right-hand use for each task in the five positions. LL:

597 extreme left, L: left, C: central, R: right, RR: extreme right. Significant interactions between

598 tasks and positions are noted by asterisks, Wald tests $* * * \mathrm{p}<0.001$.

599

600 Figure 3. Mean Handedness Indices $( \pm$ SEM) for each task in the five positions. LL: extreme

601 left, L: left, C: central, R: right, RR: extreme right. Significant correlations of individual HI

602 values between tasks are noted by an asterisk, Spearman correlation coefficient $* p<0.05$.

603

604 Figure 4. Mean absolute values of HI ( \pm SEM) for each task in the five positions. LL: extreme

605 left, L: left, C: central, R: right, RR: extreme right. Asterisks indicate significant variations of

606 ABSHI across positions (Friedman analysis of variance $* * * p<0.001$ ) and between tasks

607 (one-sample permutation test, (a) $\mathrm{p}<0.05$ ).

608 

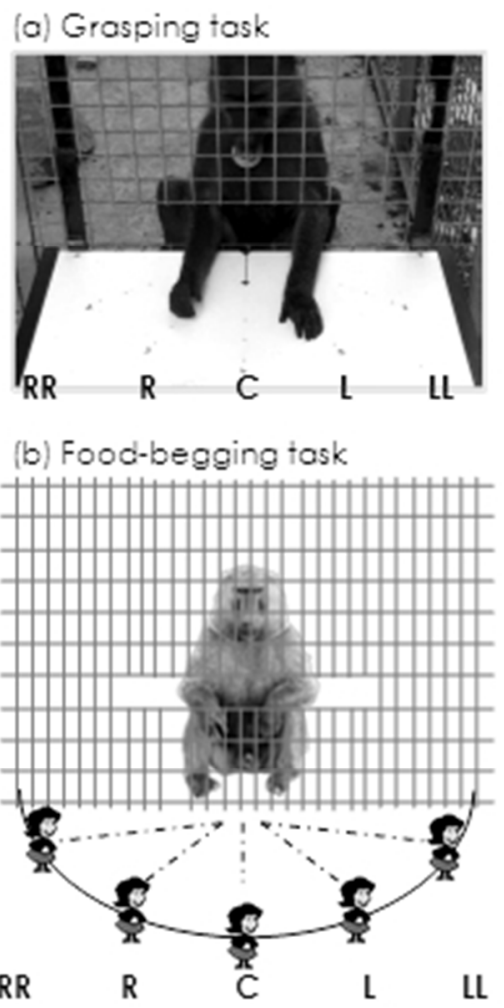

Figure 1 $21 \times 33 \mathrm{~mm}(300 \times 300 \mathrm{DPI})$ 


1
2
3
4
5
6
7
8
9
10
11
12
13
14
15
16
17
18
19
20
21
22
23
24
25
26
27
28
29
30
31
32
33
34
35
36
37
38
39
40
41
42
43
40
45
49
50
51
52
53
55
50

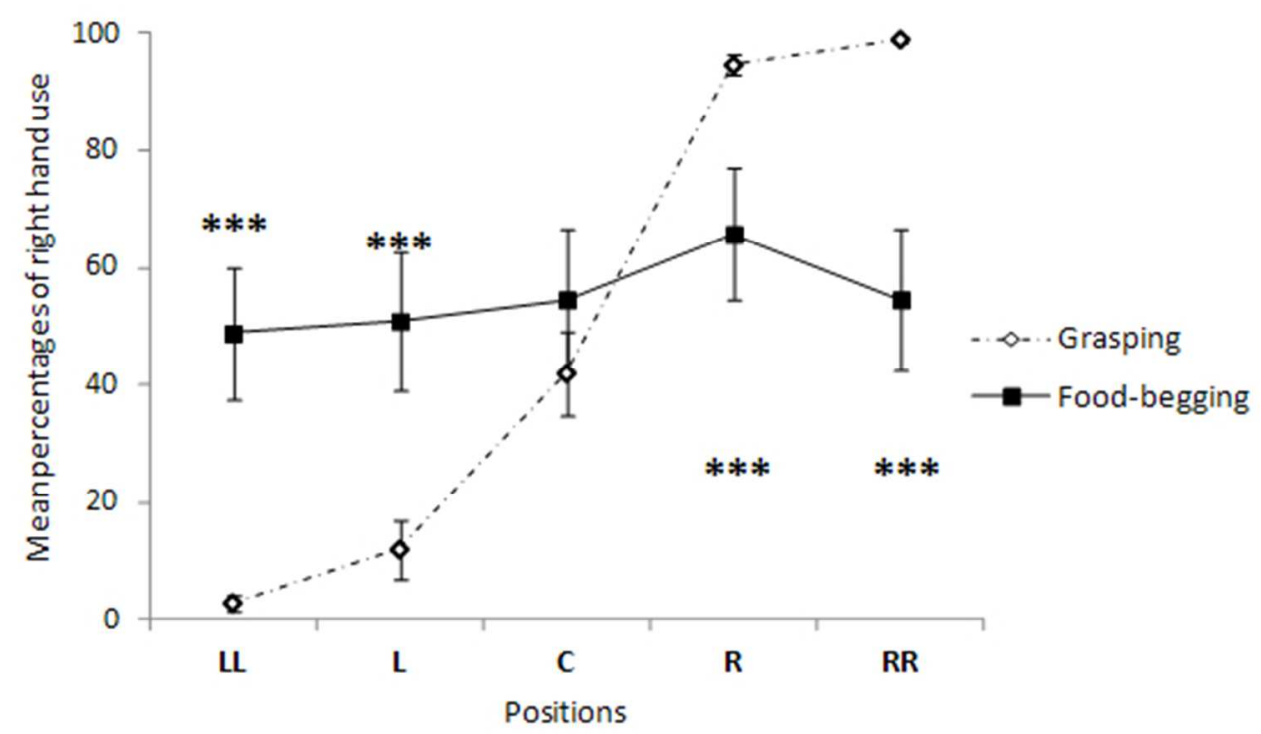

Figure 2

$48 \times 28 \mathrm{~mm}$ (300 x 300 DPI) 


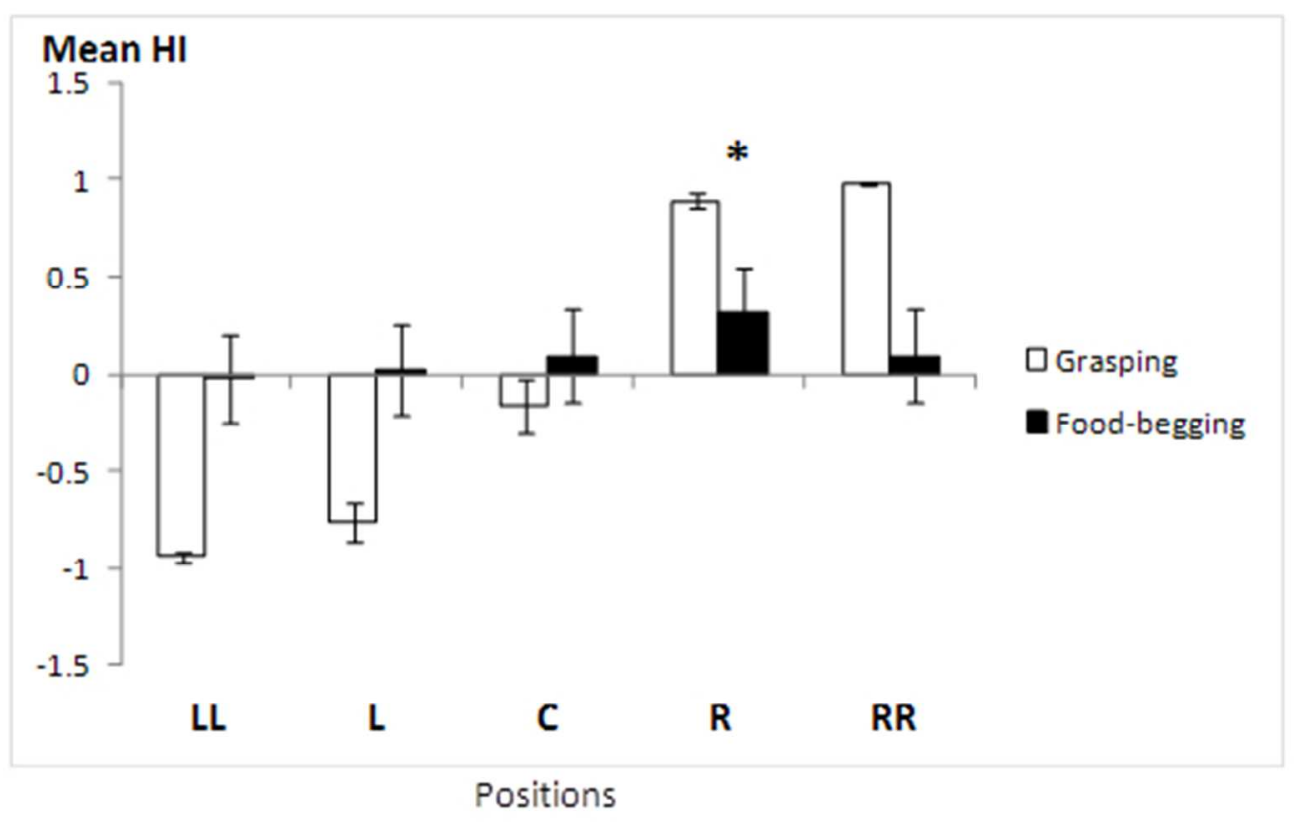

Figure 3

$41 \times 27 \mathrm{~mm}$ (300 x 300 DPI) 


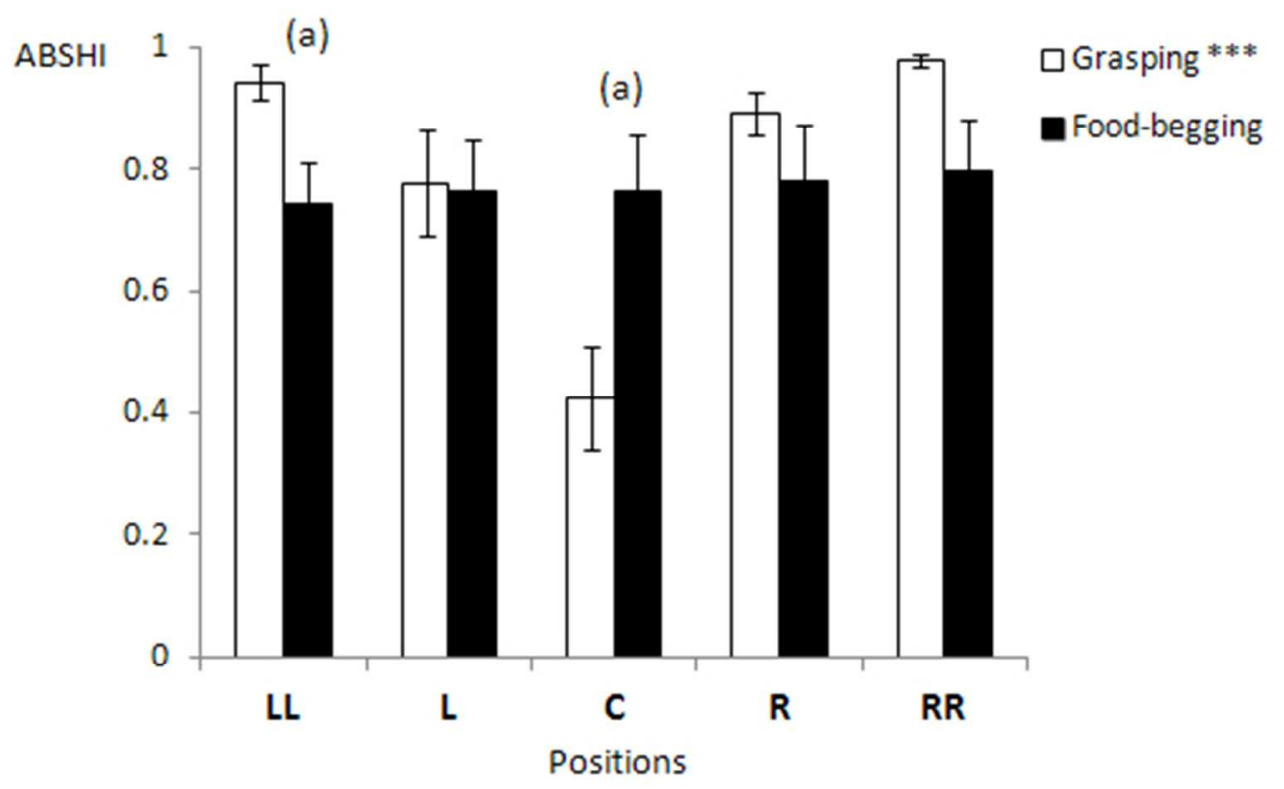

Figure 4. Mean absolute values of HI ( \pm SEM) for each task in the five positions. LL: extreme left, L: left, C: central, R: right, RR: extreme right. Asterisks indicate significant variations of ABSHI across positions (Friedman analysis of variance $* * * p<0.001$ ) and between tasks (one-sample permutation test, (a) $\mathrm{p}<$ $0.05)$. $181 \times 112 \mathrm{~mm}(72 \times 72 \mathrm{DPI})$ 